https://doi.org/10.48009/1_iis_2010_589-595

\title{
UNCHARTED WATERS: USING SOCIAL NETWORKS IN HIRING DECISIONS
}

Chris Jones, Western Illinois University, cr-jones@wiu.edu

Susan Behling, Western Illinois University, sd-behling@wiu.edu

\begin{abstract}
Social networks have become the next evolution after e-mail for communicating personal and other information. Human resource personnel are tapping into these sites and using personal information that has been posted in their hiring decisions. Instructors need to make students aware of the privacy issues with their use of social networks, and the potential impact ranging from personal image enhancement to personal image damage from inappropriate postings. This paper reviews what and how some employers use information available via social networking sites, including ethical, personal, security and legal issues associated with using and accessing social networks.
\end{abstract}

Keywords: Social Networks; Human Resources Use of Social Network Data; Ethical Issues with Social Networks

\section{INTRODUCTION}

In recent years the Internet and World Wide Web have created a communication revolution. The ability to send and receive messages, retrieve information from everywhere, and do it all at low or no cost has changed the way we work and live. Social networking is part of this phenomenon, and activity on these sites can have a far-reaching impact for users (Steffee, 2010). Sites like Facebook and Twitter are part of the new frontier, and we are making up the rules as we go (Balderrama, 2009). For many, social networking sites have become the next evolution after traditional e-mail for communicating personal and other information. An important motivating factor for joining social networking sites is to build relationships with people who may be separated by geographic boundaries, individuals that have similar interests but are unknown to each other, and to increase individual visibility. The shape of the social network (strength of the ties among users) determines the usefulness of the network to individual members (Granovetter, 2010). Based on user activity and enrolled members, Facebook, Linkedin, and Twitter are accorded strong support by the general public.

Social networks operate through web portals, which are content aggregators that provide efficient access to information and allows individuals to create and maintain a network of friends and others for personal and professional reasons. Social networking sites have low overhead, and at present do not have fees associated with building and using personal accounts on these sites. Personal profile information, pictures, artistic creations, and literally anything that can be digitized and loaded on to a computer can be made part of a social network account. All sites have a means for users to search and browse, creating a wide open environment that is not conducive to maintaining privacy. With over 400 million users, it could be argued that Facebook has a lot to lose if it erodes user privacy without user consent. In fact, data from mid-2010 suggests that traffic growth on Facebook maybe "plateauing" and privacy issues might be a key reason (McCarthy, 2010). While consumers are able to control their privacy settings with Facebook, privacy controls are highly specific and their complexity undermines their value (Wharton, 2010).

Human resource (HR) personnel are beginning to tap into these sites, and your online identity will have an impact on your job search. Some companies are giving considerable weight to the information found on these sites in the employee selection process (Lorenz, 2009). There are a number of concerns with using social networking sites for HR decision making that will be discussed. These include ethical considerations, invasion of privacy concerns, authenticity issues about the data and materials on the site, and legal issues concerning the access and use of this data in the HR decision process. Facebook is increasingly defining privacy through new features and ever changing policies, and users don't always understand what they give up in privacy when they join Facebook (Wharton, 2010). 
From an instructional perspective, it is important to make all students aware of the current environment, especially as to recruiters doing background checking of candidates through their personal social networking sites. There are no particular technology issues beyond the need to exercise caution when setting up the site and being sure to turn on whatever privacy protections are available. The larger issue is to create an awareness of the risks and exposures students face through the indiscriminate use of these sites, and the posting of material and pictures that would not enhance their image with recruiters. We will discuss several of the more important issues and concerns.

\section{SOCIAL NETWORKING}

Social networking sites are websites that connect people who share personal, professional, and other information of interest in common. Wikipedia defines a social network as a social structure made of individuals (or organizations) which are connected by one or more types of interdependency, such as friendship, kinship, common interest, sexual relationship, or relationships of beliefs (Wikipedia, 2010). There are many social networks, with three of the more commonly used being:

1. LinkedIn. This site allows members to create a profile describing their professional background.

2. Facebook. This site targets students and adults, focusing on personal matters such as families and hobbies.

3. Twitter. This site focuses on short messages, generally related to "What are you doing?" dialogue.

When you become a member of Facebook or LinkedIn you create a profile and must accept a user agreement. This profile is basically a snapshot of the member person (i.e., name, location, school history, likes, dislikes, etc...). Many of the profile responses an individual may place on the social networking web site are answers to questions that are not allowed to be asked by an employer during a hiring interview (e.g., gender, age, race, etc...). When a company accesses an individual's social networking site on the sly to find answers to these restricted questions, their actions may be creating a source of employment information that potentially could have a negative impact on an applicant. Another potential source of negative impact is many of these sites allow users to post pictures (of both themselves and others), and leave comments for the people in their network to read. When these pictures portray the individual in unflattering situations (drinking, drug use, and such) they can be used to make an unfavorable employment decision by an interviewer. Pictures also show age, perhaps family and children, and other personal information that may impact on the application review.

\section{USING SOCIAL NETWORK INFORMATION FOR EMPLOYMENT DECISION MAKING}

Once an individual is added to a person's social network, he or she has access to that person's profile. In most circumstances any picture, comment, or anything else added to the profile can be viewed by any network friend. Hence, when a company joins a person's social network list, that employer now has access to everything on that person's profile.

How does an employer know what they find on the internet is real? Because there are few controls on social networking sites, it is impossible to be sure the information was even posted by the individual. Because social networking sites contain user generated data, there is no assurance that any of the information is accurate, usually no expectation that posted information could be used in employment and hiring decisions, and unauthorized access may violate the legal rights of the individual. Under current law the employment manager is not required to notify the candidate when their social networking site is being accessed, as the information is presumed to be public (Kochman, 2009).

In addition, a person must be careful about what others post on their profiles about the candidate. For example, many of these sites allow people to "tag" their friends in photos and in videos. Tagging refers to attaching a person's name to a photo. Hence, a friend could have an embarrassing photo of you, post it on their profile without your knowledge, and tag you. Employers could potentially find that photo while conducting a search. 
For job applicants the solution to invasion of privacy is simple: don't put things on the web that represent your thinking on social, religious or political opinions that you would not want a recruiter to see (Rosen, 2008). In addition, people should carefully monitor what photos they are being tagged in. If a person is a member of Facebook, they are allowed to remove the tags (Catone, 2008).

Anything online is considered "fair game" by recruiters. Employers are now able to access information about applicants through social media that was previously not available through traditional hiring practices (Rosen, 2008). In December 2009, Facebook privacy policy changes made each Facebook user's name, profile, picture, current city, gender, networks, and list of friends publically available to other Facebook users. Only by using obscure privacy settings can a user make some, but not all, information private (Jackson, 2010). Facebook's privacy settings are very confusing, making it hard for users to restrict the information they share. In early 2010, Facebook used the opt out function rather than the opt in control, and continue to change privacy settings and procedures as they add new features (Wharton, 2010). Due to negative criticism, Facebook changed their policy in June of 2010 (Horak, 2010). With all social networking sites, setting privacy options to limit access may not prevent all unwanted users from seeing the site's content.

As the social networking phenomenon spreads, more employers are utilizing these sites to screen potential employees. In a 2009 CareerBuilder survey, $45 \%$ of employers reported using social networking sites to screen candidates. Thirty five percent found content that caused them not to hire the candidate. Negatives cited include (Lorenz, 2009):

1. Provocative or inappropriate photos

2. Comments about drinking or using drugs

3. Bad-mouthing a previous employer

4. Poor communication skills

5. Discriminatory comments

6. Lying about qualifications

7. Sharing confidential information from a previous employer
Employers use of social networking sites to search out candidate information is not limited to just the U.S. CareerBuilder has also conducted similar surveys in England and India with parallel results (Flynn, 2010; Nawoj, 2010). In England, more than $53 \%$ of employers use these sites, in India $73 \%$ of potential employers use social networking sites to find information on potential employees. The news is not all bad, however, for potential candidates. The same surveys also listed numerous reasons why employers end up hiring the candidate (Grasz, 2009):

1. Profile provided a good feel for the candidate's personality and fit

2. Profile supported candidate's professional qualifications

3. Candidate was creative

4. Candidate showed solid communication skills

5. Candidate was well-rounded

6. Other people posted good references about the candidate

7. Candidate received awards and accolades

Simply knowing potential employers are using these sites can be a benefit to candidates: they can tailor their profiles to improve their chances for getting hired. Various websites have started to provide helpful tips to candidates on using the internet in general and social networking sites in particular for finding jobs. For example, Dan Schwabel (2010) suggests using a Facebook application called "Facebook Social Ads" to advertise to potential employers.

Millions of people are interacting with others and posting information which they may believe is private and personal, only to find that access to this information may not be as restricted as they believe. Facebook attempts to balance privacy issues between making money through target advertisers, keeping users happy, and staying within what they perceive to be the law (Wharton, 2010). Recruiters will exploit this information resource as a part of the employment decision process. Online searches by employers may lead to employment decisions based on: 1) inaccurate or false information; 2) illegal or unethical information access; and 3) violations of the individual's privacy. Even if the employer adheres to the letter of the law, questions still remain whether it 
is even ethical in the first place to use these sites when making hiring decisions.

\section{SOCIAL NETWORKING USE POLICIES AND PROCEDURES}

As the popularity of social networking has soared, there has been a continual increase in organizations utilizing social networks throughout the hiring process (see above for details). This can present a number of legal issues. As discussed earlier, an employer is not allowed to find out information on a social site that it would otherwise be prohibited from asking a candidate during a traditional interview. In the United States, an employer cannot ask about a person's age, sexual orientation, religion, national origin, etc. (Kochman, 2009). All of this information is made available to employers on most people's profiles. Even if a person does not explicitly disclose it, employers can readily infer personal data from pictures and comments posted on one's profile. Even if a company does not use this protected data, a rejected candidate could still claim discrimination based on information provided on their profile. At that point, it would be difficult for employer's to prove they didn't use the information when making the final decision (Seale, 2009).

A second potential legal issue faced by employers involves the websites themselves; specifically, the user agreement the individual agrees to when registering with these sites. Many of the social networking site agreements contain language stating you will not use the site for commercial purposes. It could be argued that an employer using the site to research potential employees is, in fact, violating that agreement (Seale, 2009).

Finally, there are the unknown potential legal risks that could arise down the road. Technology is constantly changing and generally "outpaces the law" (Seale, 2009). No one really knows what type of legislation is coming with regards to the internet or, more specifically, what type of laws will be enacted with regards to using these social sites in the coming years. Employers who are using the sites now could face a whole host of legal problems if new laws come into play in the future.

Volume XI, No. 1, 2010
A more relevant concern for employers who use these sites is not the legal issues, but rather the potential ethical/moral dilemmas involved. Perhaps Donna Miller, HR Director for Rent-A-Car Europe, summed it up best by stating, "it's like going into somebody's house and searching through their cupboards" (Ceridian, 2007). This was after her company had decided they would use social networking sites to research potential candidates. The issue really speaks for itself - is it right for a company to use this "personal" information posted on these websites for viewing by friends and family, with an implicit understanding that postings would be private and not available to potential employers to research candidates?

Indeed, the answer, according to some, is yes. Marc Rotenberg, executive director of the Electronic Privacy Information Center, stated, "it's the individual's problem, it really shouldn't matter if you play in a garage band, but if you make that publicly available - why wouldn't the employer have the right to know it" (Cuesta, 2006). The message is quite clear, perhaps you would not want somebody going through your cupboards or medicine cabinet, so do not go out on the street corner and start shouting about what you have in there. You really never know who might be listening.

A second ethical issue involves "bias creep" (Seale, 2009). This is when a potential employer finds out a bit of personal information that taps into a stereotype of the employer. Eventually, that piece of information leads the employer to reject the candidate. The information could be harmless enough; perhaps the employer sees that the candidate likes a certain sports team the employer hates. Later the employer rejects the candidate based upon this. Even if it is within the law to reject based upon this information, it is really ethical to start eliminating recruits based on something like this? Can potential employers really shut off biases, stereotypes, or their general feelings when looking at this personal information? Never mind the difficult issues that could come into play if the recruiter finds the candidate physically attractive based on the photos posted.

As discussed earlier, there really is no way for employers to know if the information being posted on 
these sites is authentic. Jilted lovers, ex-friends, or just about anybody else with a personal bias could potentially post something about the candidate and that person would have little recourse. For example, a popular social website is RateMyProfessor.com, where students can go and "grade" professors and leave written comments. For college professors, there is very little that can be done to control the content of what is posted (they can post "counterarguments" if they choose). A former student, who received a bad grade, could simply say nasty things about the professor that future employers could read.

One additional conflict is that social network members want access to all the information around them, but want complete control over their own information. You can't have it both ways. Very few employers would want their personal information available to job candidates (or current employees for that matter) even if that personal information might help the candidate in deciding whether they want to work for the company or not. If the employer does not want to share that information, is it right for them to go prying into their candidates' social networking profiles to obtain this same information? Table 1 summarizes the legal and ethical issues for employers using social networking sites.

\begin{tabular}{|c|}
\hline \multicolumn{1}{c|}{ Table 1 - } \\
Legal and Ethical Considerations for \\
Employers using Social Networking Websites \\
1 - Finding prohibited information \\
2 - User agreements with websites \\
3 - Potential future laws \\
4 - Finding private information not intended for \\
employers \\
5 - Bias creep \\
6 - Finding incorrect information about candidate \\
7 - Not providing the job candidate access to the \\
employer's personal information
\end{tabular}

It is very tempting to simply say, "Do not post something if it will embarrass you in the future." The problem, however, is that the current generation has simply grown up with these sites and cannot easily distinguish between private and public information. According to Donna Seale (2009), a human rights attorney, "my experience being involved with social networking sites so far is that younger users of these

Volume XI, No. 1, 2010 sites seem less inclined to compartmentalize their lives into 'public' or 'private', 'online' or 'offline'. They just 'are' because they've grown up with this stuff. With that comes postings which might seem, to those who have less or no involvement in using social networking sites, extraordinary or inappropriate" (Seale, 2009). Couple that with the fact that most people making hiring decisions come from "older" generations who either do not participate in social networking sites or do so to a much more limited extent than the potential employees do, which leads to a culture clash. One side sees nothing wrong with posting a picture depicting them, already intoxicated, drinking another shot of whiskey last Friday; the other side sees two poor decisions - getting drunk and having someone snap a picture and, even bigger, posting the embarrassing photo online.

Although not necessarily germane to employers using social websites to screen potential employees, there are a couple of other privacy issues users of these sites should be aware of. First, Facebook had decided to disclose user information to third-parties (EPIC.org, 2010). Potentially, employers could contact these third parties to obtain relevant information even if the employer does not have access to the profiles themselves. In June of this year, Facebook changed this policy so that only public information about users is disclosed to thirdparties (Horak, 2010). It should be noted, however, that users can still allow third-parties access to private information by checking a box.

Second, as with any new technology, hiccups are inevitable. In May of this year, Facebook had a glitch that allowed users to see the "private" chats of any of their friends (Vascellaro, 2010). According to Facebook Inc., the problem was solved quickly. However, there is no telling if such a problem could arise again or impact another site. Hence, even during "private" messages online, people should take warning - you just never know what could become public.

\section{CONCLUSION}

Using social networking sites to screen employment candidates is not without risk. Recruiters and employers utilizing these sites should have written 
policies that treat candidates in a fair and nondiscriminatory manner (Rosen, 2008). Employers must craft appropriate policies and procedures regarding their use of social networking media, and apply these policies in a consistent and nondiscriminatory way (Jackson, 2010). They should avoid invading privacy or committing discriminatory acts by using social networking sites to gain access to private data. The safest policy is to notify candidates when social networking sites are searched, and how the data will be reviewed to create a cyber identity as part of the hiring process (Rosen, 2008). In addition, employers could have a third party or HR expert conduct internet background checks. They could then forward the relevant information to the people ultimately making the final decision (Kochman, 2009).

Potential candidates should carefully monitor what is put in their profiles. As a general rule of thumb, if there is any debate to whether it is tasteful - take it off. There is no need to risk not getting a job over a photo that could have been removed. In addition, a person should try to monitor if their name is being "tagged" by someone. If it is an embarrassing photo, untag themselves (if the site allows this), ask the person who tagged them to remove it, or contact the website administrator. Also, just as with a credit score, review the public information on the personal site to be sure nothing has been added or changed. We cannot control everything, but be sure to monitor what you can control when it comes to these sites.

\section{REFERENCES}

1. Balderrama, A. (2009). "Tweets are the New Homework," March 31, retrieved May 2,2010

from

http://www.theworkbuzz.com/fun-

stuff/tweets-are-the-new-homework/.

2. Catone, J. (2008). "Should Employers Use Social Network Profiles in the Hiring Process?" March 31, retrieved May 7, 2010 from

http://www.readwriteweb.com/archives/shou ld_employers_use_social_netowrking_when _hiring.php.
3. Ceridian Corporation Website (2007). "Social Networking and Recruitment," September, retrieved May 9, 2010 from http://www.ceridian.co.uk/hr/newsletter/nav/ 1,4813,593,00.html.

4. Cuesta, C. (2006). "Students Love SocialNetworking Sites and so do Employers," August 31, retrieved May 7, 2010 from http://www.foxnews.com/story/0,2933,2081 75,00.html.

5. Electronic Privacy Information Center "EPIC" (2010). "Frequently Asked Questions Regarding EPIC's Facebook Complaint, " retrieved May 7, 2010 from www.epic.org/privacy/socialnet/fbfaq.html.

6. Flynn, T. (2010). "Fifty-three Per Cent of Employers Use Social Networking Sites to Research Job Candidates, CareerBuilder.co.uk Survey Finds," January 13, retrieved May 7, 2010 from http://www.careerbuilder.ca/UK/share/about us/pressreleasesdetail.aspx ?id=pr28\&sd $=1 \%$ 2F13\%2F2010\&ed $=12 \% 2 \mathrm{~F} 31 \% 2 \mathrm{~F} 2010 \& \mathrm{cb}$ RecursionCnt $=1 \&$ cbsid=06a19467e $3944 b 27$ a6f1e32a4eacbd2f-326834872-R0-

$4 \&$ ns_siteid=ns_us_g_fifty-

three_per_cent_.

7. Granovetter, M. (1983). "Sociological Theory Chapter 7: The Strength of Weak Ties: A Network Theory Revisited," retrieved July 14, 2010 from http://citeseerx.ist.psu.edu/viewdoc/downloa $\mathrm{d}$ ?doi=10.1.1.128.7760\&rep=rep1\&type $=p d$ f.

8. Grasz, J. (2009). "Forty-five Percent of Employers Use Social Networking Sites to Research Job Candidates, CareerBuilder Survey Finds," August 19, retrieved May 7, 2010 from http://www.careerbuilder.com/share/aboutus $/$ pressreleasesdetail. asp $x$ id $=$ pr519\&sd $=8 \% 2$ f19\%2f $2009 \&$ ed $=12 \% 2 f 31 \% 2 f 2009 \&$ siteid =cbpr\&sc_cmp1=cb_pr519_. 
9. Horak, M. (2010). "Answering Recent Questions on Privacy Controls," June 18, retrieved July 11, 2010 from http://blog.facebook.com/blog.php?post=39 9994657130.

10. Jackson, T. (2010). "Social Media Permeate the Employment Life Cycle," The National Law Journal, January 11, retrieved May 3, $2010 \quad$ from www.art.com/jsp/nlj/PubArticleNLJ.jsp?id= 1202437746082\&social_media_permiate_th e_employment_life_cycle\&hbxlogin $=1$.

11. Kochman, R. (2009). "Employers - Are you Aware of the Potential Pitfalls in Using the Internet and Social Networking Sites?" December 28, retrieved May 7, 2010 from http://www.employmentlawmonitor.com/20 09/12/articles/employment-policies-andpracti/employers-are-you-aware-of-thepotential-pitfalls-in-using-the-internet-andsocial-networking-sites/.

12. Lorenz, K. (2009). "Employers are Digging up Your Digital Dirt,” August 19, retrieved May 2 from http://www.theworkbuzz.com/jobsurveys/socialnetworks/.

13. McCarthy, C. (2010). "Blame Privacy Woes for Stalled U.S. Facebook Growth?,” July 7, retrieved July 14, 2010 from http://news.cnet.com/8301-13577_320009868-36.html?tag=mncol;mlt_related.

14. Nawoj, A. (2010). "72\% of Employers Use Social Networking Sites to Research Job Candidates," January 25, retrieved May 7, 2010 from http://www.careerbuilder.co.in/Article/CB32-Job-Search-72-of-Employers-Use-SocialNetworking-Sites-to-Research-JobCandidates/?ArticleID=32\&cbRecursionCnt $=1 \&$ cbsid $=7431 \mathrm{ffaffcc} 74019910404 \mathrm{ac} 8 \mathrm{ee} 42$ 45e-326835563-R6-

4\&ns_siteid=ns_us_g_72\%25_of_employer s_us_.

Volume XI, No. 1, 2010
15. Rosen, L. (2008). "Caution! Using Search Engines, MySpace of Facebook for hiring Decisions May be Hazardous to Your Business," June, retrieved May 2 http://www.esrcheck.com/articles/cautionusing-search-engines-MySpace-or-

Facebook-for-hiring-decisions-may-beharzardous-to-your-business.php.

16. Schawbel, D. (2009). "7 Secrets to Getting Your Next Job Using Social Media," January 5, retrieved May 9, 2010 from http://mashable.com/2009/01/05/job-searchsecrets/.

17. Seale, D. (2009). "Using Social Networking Sites in the Hiring Process: Smart Move or Human Rights Trap? - Part One," January 26, retrieved May 7, 2010 from http://donnasealeconsulting.typepad.com/wo rkplacehumanrights/2009/01/using-socialnetworking-sites-in-the-hiring-processsmart-move-or-human-rights-trap.html.

18. Seale, D. (2009). “Using Social Networking Sites in the Hiring Process: Smart Move or Human Rights Trap? - Part Two," January 29, retrieved May 7, 2010 from http://donnasealeconsulting.typepad.com/wo rkplacehumanrights/2009/01/using-socialnetworking-sites-part-two.html.

19. Steffee, S. (2010). "Leveraging Social Media," Internal Auditor, February.

20. Vascellaro, J. (2010). "Facebook Rushes to Fix Glitch that Exposed Private Chats," The Wall Street Journal, May 6.

21. Knowledge at Wharton (2010). "Act Now, Apologize Later: Will Users 'Friend' Facebook's Latest Intrusion on Privacy," May 12, retrieved May 12, 2010 from http://knowledge.wharton.edu/article.cpm?ar ticleid=2482.

22. Wikipedia. "Social Networking," retrieved May 2, $2010 \quad$ from http://en.wikipedia.org/wiki/social_network. 